\title{
A New Example of Edge-to-Face Interaction of Aromatic Rings in Oligopeptides: Cyclolinopeptide A
}

\author{
Ignacy Z. Siemion \\ Institute of Chemistry, Wrocław University, Joliot-Curie 14, 50-383 Wrocław, Poland \\ Z. Naturforsch. 45b, 1324-1326 (1990); received March 27, 1990 \\ Cyclolinopeptide A, NMR Spectra, Edge-to-Face Interaction \\ The analysis of the aromatic region of ${ }^{1} \mathrm{H}$ and ${ }^{13} \mathrm{C}$ NMR spectra of cyclolinopeptide $\mathrm{A}$ \\ (cyclic nonapeptide with the sequence $\mathrm{c}-($ Pro-Pro-Phe-Phe-Leu-Ile-Ile-Leu-Val-), \\ (CLA)) shows that $\mathrm{Phe}-3$ and $\mathrm{Phe}-4$ aromatic rings are oriented nearly perpendicularly to each \\ other, forming edge-to-face pair. It signifies the strong limitation of the free rotation of \\ aromatic residues, probably because of the steric hindrance exerted by proximal aliphatic side \\ chains of CLA.
}

\section{Introduction}

It is known $[1,2]$ that aromatic side-chains in proteins pair with preferred centroid separations of $3.4-6.5 \AA$. The rings in pairs are oriented nearly perpendicularly to each other (edge-to-face orientation). This orientation is caused by the interaction of positively polarized hydrogen atoms of one ring with the $\pi$-electron cloud of the other. Such a spatial arrangement of the aromatic rings appears also in the crystals of such compounds of low molecular weight as N-phenyl-acetylL-phenylalanine [3] and L-phenylalanine benzyl ester monochloride [4], as well as in crystals of L-phenylalanyl-glycyl-glycyl-D-phenylalanine trihydrate [5]. The edge-to-face aromatic ring interaction involving the Tyr-228 residue of chymotrypsin was found in the complex of this enzyme with its inactivator 5-benzyl-6-chloro-2-pyrone [6]. In the crystals of pressinoic acid (the cyclic moiety of vasopressin) the planes of Tyr-2 and Phe-3 aromatic rings are inclined to each other by $72^{\circ}$ and their geometric centers are separated by $4.78 \AA$ [7]. The similar effect was observed by NMR spectroscopy for $\mathrm{d}_{6}$-DMSO solution of somatostatin (the interaction between Phe-6 and Phe-11 residues) [8]. On the basis of our experiments with "azo-enkephalin" (an enkephalin analogue in which Tyr-1 and Phe- 4 residues were linked by the azo-bridge) we postulated existence of the similar orientation of aromatic rings in the biologically active conformation of enkephalin [9]. In fact, a quasi-orthogonal contact of these residues was found recently

Verlag der Zeitschrift für Naturforschung, D-7400 Tübingen 0932-0776/90/0900-1324/\$01.00/0 in the crystals of leucine-enkephalin trihydrate [10].

In the last time the similar effects were found by us also in the case of cyclolinopeptide A (CLA). CLA is a cyclic nonapeptide isolated in 1959 from linseed oil [11]. It possesses the sequence:

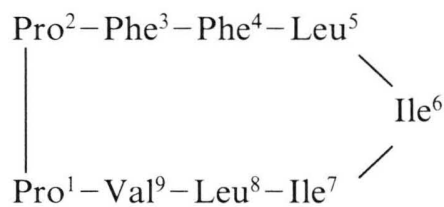

In 1977 we found [12] that there is a cis-amide bond between $\mathrm{Pro}^{1}$ and $\mathrm{Pro}^{2}$ residues. This finding was recently confirmed by X-ray studies $[13,14]$ and also be NMR measurements [15].

\section{Results and Discussion}

In the region of aromatic proton signals of ${ }^{1} \mathrm{H}$ NMR spectrum of CLA in $d_{6}$-DMSO (see Fig. 1) there is a broad multiplet at $7.11-7.30 \mathrm{ppm}$ and a resonance connected with two protons shifted to higher field values $(6.885 \mathrm{ppm})$. It can correspond to the resonance of $\mathrm{H}-2,6$ or $\mathrm{H}-3,5$ atoms of one aromatic ring. The similar picture is seen also in $\mathrm{CD}_{3} \mathrm{OD}$ solution (Fig. 1); the high-field shift of the discussed resonance is, however, lower here than in DMSO. The signal appears at $7.13 \mathrm{ppm}$ as a well resolved doublet with the ${ }^{3} J_{2,3}$ coupling constant of $7.13 \mathrm{~Hz}$. The broad multiplet occupies the region between $7.21-7.30 \mathrm{ppm}$. The distance of the doublet from the low-field limit of the multiplet is $0.17 \mathrm{ppm}$, whereas for DMSO it was equal to $0.415 \mathrm{ppm}$. The doublet-structure of the highfield signal allows to identify it as the resonance of H-2,6 atoms. 


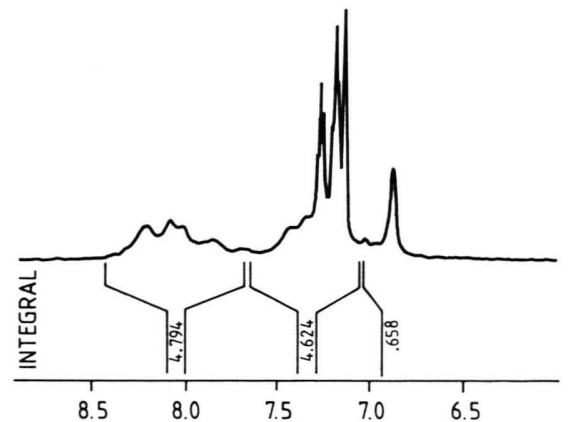

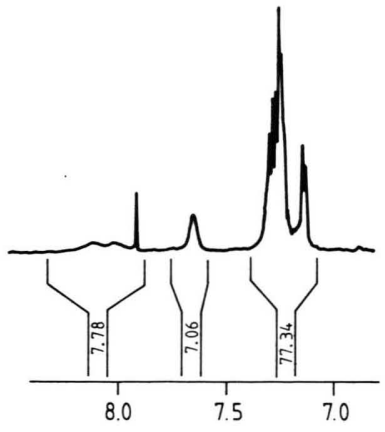

Fig. 1. The aromatic region of ${ }^{1} \mathrm{H}$ NMR spectra of CLA dissolved in $\mathrm{d}_{6}$-DMSO (left) and $\mathrm{CD}_{3} \mathrm{OD}$ (right).
There is no doubt that the observed effect results from the ring-current shielding, exerted by one aromatic ring on the other. The effect diminishes upon transition from DMSO to $\mathrm{CD}_{3} \mathrm{OD}$ solution.

The similar picture may be seen in ${ }^{13} \mathrm{C}$ NMR spectra of CLA. The carbon atoms of both aromatic rings differ slightly in their chemical shifts and give two sets of resonances. The resonances were assigned using the data compiled in [16], as well as using $2 \mathrm{D}$ carbon-proton shifts correlations. The data are summarized in Table I. The greatest chemical shift difference $\Delta \delta$ was observed for $\mathrm{C}-2,6$ atoms of both rings $\left(0.4 \mathrm{ppm}\right.$ in $\mathrm{CD}_{3} \mathrm{OD}$ solution). It suggests that the shielding of one ring by the other influences mainly these positions of the aromatic ring. It is known that the absolute magnitude of the ring-current effect is the same for ${ }^{13} \mathrm{C}$ as for ${ }^{1} \mathrm{H}$ nucleus, if they occupy the same positions in space relative to the aromatic $\pi$-electron cloud $[17,18]$. The effects observed by us in ${ }^{13} \mathrm{C}$ and ${ }^{1} \mathrm{H}$ NMR spectra are really comparable in their magnitudes.

$2 \mathrm{D}$ carbon-proton shift correlation (Fig. 2) performed for $\mathrm{d}_{6}$-DMSO solution, enables the identi-

Table I. ${ }^{13} \mathrm{C}$ NMR data of aromatic nuclei of CLA (in ppm).

\begin{tabular}{lllllll}
\hline & \multicolumn{2}{l}{$\begin{array}{l}\mathrm{d}_{6} \text {-DMSO } \\
\text { Resonance } \\
\text { chem. shift }\end{array}$} & $\Delta \delta$ & \multicolumn{2}{l}{$\begin{array}{l}\mathrm{CD}_{3} \mathrm{OD} \\
\text { chem. shift }\end{array}$} & $\Delta \delta$ \\
\hline $\mathrm{C}-1$ & 137.66 & 137.38 & 0.28 & 138.69 & 138.45 & 0.24 \\
$\mathrm{C}-2,6$ & 128.65 & 128.48 & 0.17 & 130.49 & 130.09 & 0.40 \\
$\mathrm{C}-3,5$ & 127.88 & 127.61 & 0.27 & 129.70 & 129.51 & 0.19 \\
C-4 & 126.06 & 125.74 & 0.32 & 128.06 & 127.79 & 0.27 \\
\hline
\end{tabular}

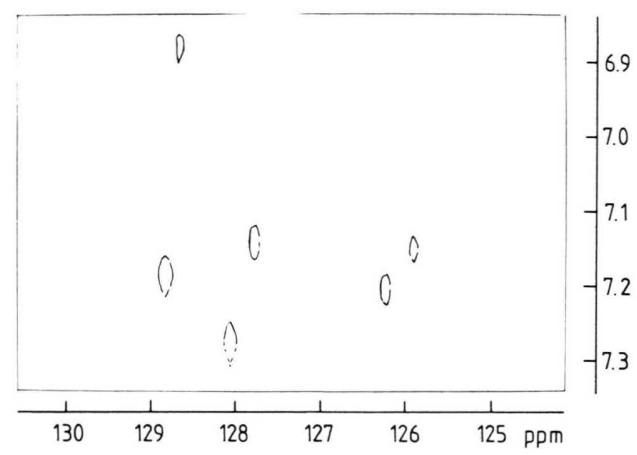

Fig. 2. 2D Carbon-proton shifts correlation for aromatic nuclei of CLA $\left(\mathrm{d}_{6}-\mathrm{DMSO}\right)$.

fication of the positions of aromatic hydrogen resonances of both Phe residues. They are as follows:

$\mathrm{H}-2,6 \quad 7.185$ and 6.885 , shift difference $0.30 \mathrm{ppm}$ $\mathrm{H}-3,5 \quad 7.27$ and 7.14 , shift difference $0.13 \mathrm{ppm}$ $\mathrm{H}-4 \quad 7.20$ and 7.15, shift difference $0.05 \mathrm{ppm}$.

It is very interesting that the chemical shift difference diminishes regularly on going from $\mathrm{H}-2,6$ to $\mathrm{H}-4$. Thus, the shielding effect is the greatest for 2,6-positions of the ring. It is lowered for 3,5-positions, and is minimal for the 4-position. It gives some orientation about the mutual spatial arrangement of both aromatic rings. It must be noted, however, that so such regularity was observed in the ${ }^{13} \mathrm{C}$ NMR spectrum.

The presented observations enable to make the following conclusions: Both aromatic rings (Phe-3 and Phe- 4 side chains) appear on the same side of the peptide ring plane. The free rotation of aromatic side chains is limited, probably because of the steric hindrance exerted by other (aliphatic) 
side chains of the peptide. It suggests that phenylalanine rings contact the aliphatic side chains of other amino acid residues, which are present in the peptide.

The edge-to-face interaction of Phe residues in CLA results from the cyclic structure of the peptide. No similar effect was observed in the ${ }^{1} \mathrm{H}$ NMR spectrum of linear peptide: H-Leu-Ile-Ile-Leu-Val-Pro-Pro-Phe-Phe-OH. All aromatic hydrogen atom resonances are localized in this case between 7.14-7.25 ppm and no high-field shifted component can be observed in the spectrum.

\section{Experimental}

The linear nonapeptide

H-Leu-Ile-Ile-Leu-Val-Pro-Pro-Phe-Phe-OH was synthesized by solid-phase method using Merrifield's resin. The product was split from the resin by the mixture of trifluoroacetic acid and sulphuric acid and cyclized with Castro's reagent [19]. Cyclic nonapeptide was purified by washing in ethyl acetate with $1 \mathrm{~N} \mathrm{NaOH}$ and $1 \mathrm{~N} \mathrm{HCl}$ and water, and then by preparative HPLC. Its physicochemical data were in accord with [20].

NMR measurements were performed with Bruker spectrometer, operating with the frequences of $500 \mathrm{MHz}\left({ }^{1} \mathrm{H} \mathrm{NMR}\right)$ and $125 \mathrm{MHz}\left({ }^{13} \mathrm{C} \mathrm{NMR}\right)$. The measurements were performed at room temp.; $5 \%$ solutions of the peptides in proper solvents were used. The data are expressed in TMS scale.

I am grateful to Dr. A. Kubik (Chemistry Institute, Wrocław University) for her help in CLA preparation.
[1] S. K. Burley and G. A. Petsko, J. Am. Chem. Soc. 108, 7995 (1986).

[2] S. K. Burley and G. A. Petsko, Science 229, 237 (1985).

[3] S. K. Burley and A. H. J. Wang, Acta Crystallogr. C 43, 797 (1987).

[4] A. H. J. Wang and S. K. Burley, Acta Crystallogr. C 43, 1011 (1987).

[5] S. Fujii, S. K. Burley, and A. H. J. Wang, Acta Crystallogr. C43, 1008 (1987).

[6] D. Ringe, B. A. Seaton, M. H. Gelb, and R. H. Abeles, Biochemistry 24, 64 (1985).

[7] D. A. Langs, G. D. Smith, J. J. Stezowski, and R. E. Hughes, Science 232, 1240 (1986).

[8] B. H. Arison, R. Hirschmann, W. J. Palevoda, S. F. Brady, and D. F. Veber, Biochem. Biophys. Res. Commun. 100, 1148 (1981).

[9] I. Z. Siemion, Z. Szewczuk, Z. Herman, and Z. Stachura, Mol. Cell. Biochem. 34, 23 (1981).

[10] A. Aubry, N. Birlirakis, M. Sakarellos-Daitsiosis, C. Sakarellos, and M. Marraud, J. Chem. Soc. 1988, 963.

[11] H. P. Kaufmann and A. Tobschirbel, Ber. Dtsch. Chem. Ges. 92, 2805 (1959).
[12] I. Z. Siemion, W. A. Klis, A Sucharda-Sobczyk, and R. Obermeier, Roczniki Chem. 51, 1489 (1977).

[13] B. DiBlasio, E. Benedetti, V. Pavone, and C. Pedone, Biopolymers 26, 2099 (1987).

[14] B. S. Neela, M. V. Mangula, S. Ramakumar, D. Balasubramanian, and M. A. Viswanitra, Biopolymers, in press.

[15] S. Ragothama, C. Ramakrishnan, D. Balasubramanian, and P. Balaram, Biopolymers 28, 573 (1989).

[16] E. Breitmaier and W. Voelter, Carbon-13 NMR Spectroscopy, 3-d Ed., Verlag Chemie, WeinheimNew York (1987).

[17] R. du Vernet and V. Boekelheide, Proc. Natl. Acad. Sci. USA, 71, 2961 (1974).

[18] R. Deslauriers, Z. Grzonka, K. Schaumburg, T. Shiba, and R. Walter, J. Am. Chem. Soc. 97, 5093 (1975).

[19] B. Castro, J. R. Dormoy, G. Evin, and C. Selve, Tetrahedron Lett. 1975, 1219.

[20] R. Obermeier, PhThesis, Technische Universität München, München (1969). 